Proceedings of the 1954 Glasgow Conference on Nuclear and Meson Physics

Edited by E. H. Bellamy and R. G. Moorhouse. (Conference sponsored by the International Union of Pure and Applied Physics.) Pp. ix $+352+5$ plates. (London and New York: Pergamon Press, Ltd., 1955.) 63s. net.

THIS record of the 1954 Glasgow conference on nuclear and meson physics sponsored by the International Union of Pure and Applied Physics is divided into eight sections. The first four of these sections, which deal with nuclear constitution, properties and problems, occupy some two-thirds of the volume, while Part 5 collects the papers on $\pi$-mesons and Part 6 contains a few papers under the heading of field theory. The last two sections, dealing respectively with high-energy experimental techniques and with heavy mesons and hyperons, although short, are far from being the least interesting sections. Some particularly striking photographs illustrate Hildebrand's paper on bubble chambers.

Generally, each section of the book is introduced by one or two review papers; these give a comprehensive survey of the state of nuclear and meson physies in July 1954. Of some ninety other papers, the majority report on experimental results current at the time of the conference and discuss the implications of these results. As presented in the book, individual papers range in length from a fow lines to several pages, and, although the space allocated to the various papers is not always an indication of their relative value, the editors and the publisher must be congratulated in making available a very adequate and readable account of the proceedings of the conference. Some significant points emerge in the edited version of the discussion which follows many of the papers.

To the many who may wish on occasion to use this book for reference purposes, the lack of an index will constitute a handicap. Paper titles, as listed at the beginning of the volume, are not in general a sufficient guide to the content of the papers. I feel that the extra labour required to index the subject. matter adequately would have made a useful book more valuable.

J. C. BOWER

\section{A History of Red Tape}

An Account of the Origin and Development of the Civil Service. By Sir John Craig. Pp. vii $+211+$ 12 plates. (London: Macdonald and Evans, Ltd., 1955.) 18s. net.

CIR JOHN CRAIG'S engaging account of the $\$$ origin and development of the British Civil Service, as its sub-title indicates, goes farther back than E. W. Cohen's standard book, but makes no attempt to cover the decade and a half since that book was published, nor can it claim to be as serious a historical study. It is instead a readable and entertaining essay in which the author makes no attempt to disguise his own views and prejudices, particularly against the Trevelyan-Northcote reforms. On that question, and on the recruitment to the Civil Service by open competition, his highly critical remarks should be read in the light of Sir Edward Bridge's observations on the reforms of 1854 in a recent issue of the Political Quarterly, or of Prof. K. C. Wheare's lecture on "The Civil Service in the Constitution" to the University of London in 1954. Nevertheless, they remind the reader that there is another side and sound a note of caution to over- enthusiastic advocates of changes in methods of recruitment which $R$. K. Kelsall's recent study might stimulate. Sir John presents an immense array of facts in a most attractive guise and from an unusual angle, nor is the detail ever allowed to confuse the reader or his own prejudices to distort the picture. To the discussion on the adequacy of the Civil Service to the needs of to-day or the changes required in organization or elsewhere to increase its efficiency, his book makes no contribution, except in so far as it gives a clear understanding of how the Civil Service came to be, and a warning as to directions in which change or reform requires caution and great care. There are an interesting list, up to the end of the nineteenth century, of literary men who held posts in the Civil Service, and a short bibliography that is remarkable no less for the inclusions than for the omissions.

R. B.

\section{Ferromagnetic Domains}

By Dr. K. H. Stewart. (Cambridge Monographs on Physies.) Pp. xi $+176+7$ plates. (Cambridge: At the University Press, 1954.) 25s. net.

TN his preface, Dr. K. H. Stewart states that "this book attempts to give a coherent outline of the fundamentals of domain bohaviour ...", and in the reviewer's opinion he has succeeded in giving a clear survey of the subject. It must be pointed out that the book was published more than a year ago, with the preface dated October 1953, and that there are few references to papers published after 1952.

An introductory chapter deals with the domain hypothesis and its implications, and then magnetocrystalline anisotropy, magnetostriction and the effects of stresses on magnetic properties are dealt with in some detail. There follow chapters on domain arrangements, with particular reference to single crystals, on the widths of, and energies in, domain walls, and on the factors affecting domain wall movement. The final two chapters briefly discuss time effects in magnetization and thermal energy changes involved in magnetization processes.

This is essentially a review of a subject which has expanded considerably in post-war years, and in only 170 pages a reader must expect some aspects to be dealt with most briefly. In particular, experimental detail-for example, the technique of producing domain powder patterns-has been reduced to the minimum. The book is well written and produced, and is fully illustrated with clear, though often rather small, diagrams. It will be of value to many, especially those whose interests lie on the fringe of this field and whose knowledge might otherwise end there. The information can easily be brought to the present date by consulting, for example, recent Proceedings of the Physical Society.

\section{A Cuckoo in the House}

By Maxwell Knight. Pp. ix $+80+6$ plates. (London: Methuen and Co., Ltd., 1955.) 7s. 6d. net.

R. MAXWELL KNIGHT took a young cuckoo 1 from the nest of its foster parents and brought it up by hand. It became quite domesticated and very confiding. It was allowed full freedom and flew where it pleased, but remained with him until migration time, when after a display of restlessness it disappeared. In this little book, illustrated with some excellent photographs, he tells about the bird, its disposition and behaviour, discussing at the same time various cuckoo problems and bird problems in general. 